Article

\title{
Isolation of a Novel Metalloproteinase from Agkistrodon Venom and Its Antithrombotic Activity Analysis
}

\author{
Jin Huang ${ }^{1, \dagger}{ }^{+}$Hui Fan ${ }^{1,+}$, Xiaojian Yin ${ }^{1,2, *}$ and Fang Huang ${ }^{1,2, *}$ \\ State Key Laboratory of Natural Medicines, China Pharmaceutical University, Nanjing 210009, China \\ 2 Chinese Medicine College, China Pharmaceutical University, Nanjing 210009, China \\ * Correspondence: xiaojian@cpu.edu.cn (X.Y.); huangfang@cpu.edu.cn (F.H.); Tel.: +86-25-86185559 (X.Y.); \\ +86-181-5162-0528 (F.H.); Fax: +86-25-83271379 (X.Y.) \\ + These authors contributed equally to this work.
}

Received: 1 July 2019; Accepted: 18 August 2019; Published: 21 August 2019

\begin{abstract}
Snake venom contains large amounts of active proteins and peptides. In this study, a novel snake protein, metalloproteinase SP, was successfully isolated from the venom of Agkistrodon acutus by multi-gel chromatography. The isolated protein exhibits anti-platelet aggregation activity. Animal experiments showed that it exhibited defibration, anticoagulation, and antithrombotic effects and contributes to improved blood rheology and antiplatelet aggregation. In vivo experiments demonstrated that it prolonged clotting time, partial thromboplastin time, prothrombin time, thrombin time, fibrinogen time and reduced fibrinogen content of mice. Also, metalloproteinase SP inhibited carrageenan-induced tail thrombosis, ADP-induced acute pulmonary embolism, and ADP, Arachidonic acid (AA), or collagen-induced platelet aggregation. In vitro experiments showed that the protein cleaved the $\alpha, \beta$, and $\gamma$ chains of fibrinogen. Metabolomic analysis upon metalloproteinase SP treatment revealed that 14 metabolites, which are mainly involved in phenylalanine, tyrosine, and tryptophan biosynthesis, responded to metalloproteinase SP treatment. In summary, the isolated snake venom protein inhibits formation of acute pulmonary embolism probably through regulating and restoring perturbed energy, lipid, and amino acid metabolism.
\end{abstract}

Keywords: Agkistrodon venom; metalloproteinase; fibrinogen; antithrombotic; metabolomics

\section{Introduction}

Thrombotic disease is one with a high morbidity and mortality rate in the world, accounting for approximately $40 \%$ of deaths yearly [1]. Thrombotic diseases include pulmonary embolism (PE), deep vein thrombosis (DVT), myocardial infarction, coronary atherosclerosis, ischemic stroke, and so on $[2,3]$. The formation of thrombus is closely related to platelet aggregation, blood coagulation, and fibrin network formation. At present, antithrombotic drugs are categorized into three groups: anti-platelet aggregation drugs, anticoagulants, and thrombolytic drugs.

Evidence from recent research indicates that snake venom contains many active protein or peptides with defibration, anticoagulation, antiplatelet aggregation, and antithrombotic functions [4]. The anti-thrombotic action of snake venom protein is due to its ability to cleave the fibrinogen, reduce the content of fibrinogen, activate fibrinolytic enzyme, inhibit the activation of FXa, FIIa, thrombin, and other coagulation factors [5-7]. A large number of snake venom protease components have been isolated and some snake venom preparations are widely used in clinical practice.

Deinagkistrodon is one of the most virulent snake species in China that mostly lives in China's coastal and southwestern regions $[8,9]$. Snake venom contains a variety of active ingredients related 
to blood coagulation, such as phospholipase A2, serine protease, thrombin, metalloproteinase, and thrombin-like protein. Several new proteases and peptides have been isolated from the venom of Agkistrodon, such as Agacutas, Pt-A (Glu-Asn-Trp), Pt-B (Glu-Gln-Trp), ACH-11 [10-12]. These proteases affect many coagulation factors and cascades in the hemostatic system, such as cleavage of the alpha or beta chain of fibrinogen, inhibition of FXa, and activation of plasmin [13]. Most of the studied venomous snake venom polypeptides belong to serine proteases rather than metalloproteinases [14]. Metalloproteinases constitute an important components of the Agkistrodon genus. Metalloproteinase is an essential anticoagulant factor and exhibits fibrinogenolytic activity. However, there are few studies on the isolation and characterization of metalloproteinases from the venom of snakes belonging to the Agkistrodon genus. There is also paucity of information on the pharmacological effects of the isolated metalloproteinases. Metabolomics is an emerging discipline that compares the changes in body metabolites under different physiological and pathological conditions. In recent years, metabolomics has been widely used in drug research. It can be applied to study the mechanism of drug action by examining the changes of metabolic components in the body using serum, urine, and tissue fluid. It has been widely used in the study of monomeric compounds and traditional Chinese medicinal compounds. This study, to our best knowledge, is the first to report the anti-thrombotic effect mechanism of snake venom monomer using metabolomics

This work aimed to isolate and purify a novel metalloproteinase SP, determine its chemical properties and amino acid sequence, and investigate its pharmacological effects via in vivo studies. In order to study the mechanism of action of the novel snake venom protein, we investigated its antithrombotic effect using fibrinogen solubilization assay combined with UPLC-Q/TOF-MS-based non-targeted plasma metabolomics.

\section{Results}

\subsection{Isolation of Metalloproteinase SP from Agkistrodon Venom}

Based on the molecular weight differences of the snake venom proteins, an efficient separation and purification was achieved by the functional group ion exchange. The metalloproteinase SP snake venom monomer was then isolated and purified by sequential preparation, including ultracentrifugation, molecular exclusion chromatography on Sephadex TM G-75 (Figure 1A), anion exchange chromatography on DEAE-SphadexA-50 (Figure 1B), Sephadex TM G-75 (Figure 1C), and ultrafiltration.

\subsection{Protein Identification}

Based on LC-MS/MS analysis and database search analysis, it was found that three specific amino acid sequence fragments including SFGEWR, STEFQR, ENPPCILNKP were identified to belong to metalloproteinase SP (Figure 1D and Figure S1). Metalloproteinase SP consists of 202 amino acids with a molecular weight of $22.945 \mathrm{KDa}$ and an isoelectric point of 5.78 .

\subsection{Anti-Thrombotic Activity}

\subsubsection{Anti-Coagulant Activity}

Compared to the control group, the coagulation time after metalloproteinase SP treatment was significantly prolonged $(* * *<0.001$, Figure $2 \mathrm{~A}, \mathrm{~B})$. Anticoagulant activity of metalloproteinase SP was evaluated by the classical coagulation assays. The parameters including activated partial thromboplastin time (APTT), thrombin time (TT), prothrombin time (PT), and Fibrinogen time (FT) were checked (Figure 2C-F). Metalloproteinase SP protein also significantly prolonged the clotting time, which inevitably influenced the changes in blood components and affect blood rheology (Tables 1 and 2). 

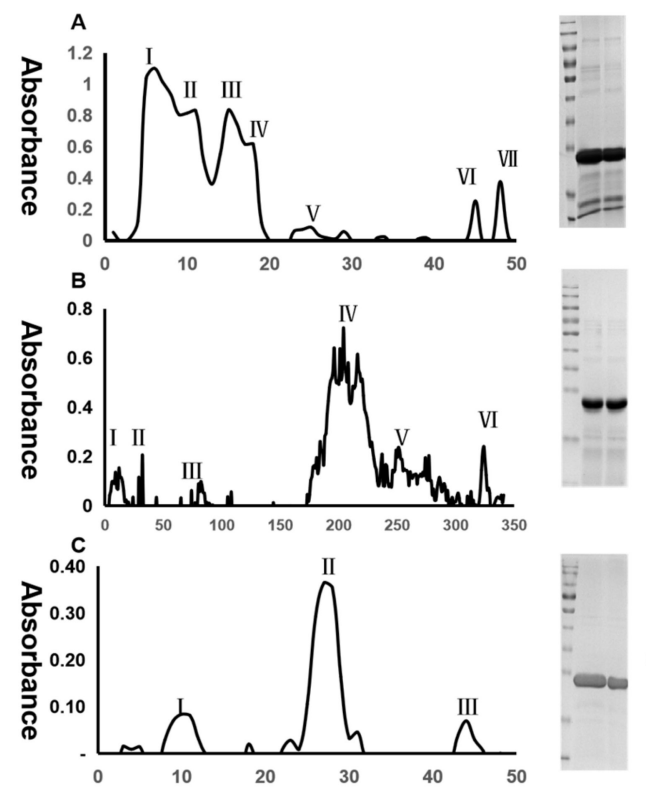

STEFQRYMEIVIVVDHSMVKKYNGDSPKI KAWVYEMINTITEGYRDLYIDIILSGLEIW SEKDLINVEASAGNTLKSFGEWRAKDLIH RISHDNAQLLTATDFDGPTIGLAYVASMCE PKLSVGVIQDHSSVNRLVAITLAHEMAHN LGVRHDEKDCVGVVYLCIMRIPVVEDKR SYFSDCSYIQCREYI SKENPPCILNKP

Figure 1. Isolation of metalloproteinase SP from Agkistrodon venom. (A) Snake venom (1000 mg) was subjected to Sephadex TM G-75 chromatography $(1 \times 100 \mathrm{~cm})$ by eluting with $5 \mathrm{mM}$ Tris-HCl ( $\mathrm{pH}$ 7.4). The fraction III contains the target molecular weight protein. (B) Fraction III was further subjected to separation on DEAE-SphadexA-50 column $(2 \times 150 \mathrm{~cm})$, eluted with $5 \mathrm{mM}$ Tris- $\mathrm{HCl}(\mathrm{pH}$ 7.4) and a segmented concentration gradient of $0.2 \mathrm{M} \mathrm{NaCl}$. The fraction I contain the target molecular weight protein. (C) Fraction I was then separated on Sephadex TM G-75 column $(1 \times 50 \mathrm{~cm})$, with $5 \mathrm{mM}$ Tris- $\mathrm{HCl}$ ( $\mathrm{pH} 7.4$ ). Fraction II of this separation contains the target molecular weight protein. M, marker of protein molecular weight. (D) The peptide sequence of targeted protein. Red colors indicated unique peptides identified by LC-MS/MS, matching to targeted protein.

Table 1. Hemodynamic examination of arterial blood in clopidogrel and metalloproteinase SP treated mice.

\begin{tabular}{|c|c|c|c|c|c|c|c|}
\hline & $\begin{array}{l}\text { Red Blood } \\
\text { Cell Count } \\
\left(10^{12} / \mathrm{L}\right)\end{array}$ & $\begin{array}{c}\text { Hematocrit } \\
(\%)\end{array}$ & $\begin{array}{l}\text { Blood Platelet } \\
\text { Count }\left(10^{9} / \mathrm{L}\right)\end{array}$ & $\begin{array}{l}\text { Plateletcrit } \\
\quad(\%)\end{array}$ & $\begin{array}{l}\text { Mean Platelet } \\
\text { Volume (fL) }\end{array}$ & $\begin{array}{l}\text { Platelet Volume } \\
\text { Distribution } \\
\text { Width (\%) }\end{array}$ & $\begin{array}{c}\text { Platelet } \\
\text { Larger Cell } \\
\text { Ratio (\%) }\end{array}$ \\
\hline Blank & $5.50 \pm 0.29$ & $29.4 \pm 1.81$ & $812 \pm 36.7$ & $0.440 \pm 0.03$ & $5.45 \pm 0.16$ & $4.15 \pm 0.20$ & $5.93 \pm 0.93$ \\
\hline $\begin{array}{c}\text { Metalloproteinase } \\
\text { SP }\end{array}$ & $5.47 \pm 0.20$ & $28.9 \pm 0.96$ & $777 \pm 26.5$ * & $0.410 \pm 0.02 * *$ & $5.42 \pm 0.27$ & $4.21 \pm 0.30$ & $6.45 \pm 0.26$ \\
\hline
\end{tabular}

In the clopidogrel sulfate treated group, the platelet-larger cell ratio was decreased compared with the blank group. In the metalloproteinase SP group, the platelet count and plateletcrit were decreased compared to the blank group. All data were expressed as mean \pm SD. ${ }^{*} p<0.05,{ }^{* *} p<0.01$, and ${ }^{* * *} p<0.001$ compared with the blank control.

Table 2. Hemodynamic examination of venous blood in clopidogrel and metalloproteinase SP treated mice.

\begin{tabular}{|c|c|c|c|c|c|c|c|}
\hline & $\begin{array}{c}\text { Red Blood } \\
\text { Cell Count } \\
\left(10^{12} / \mathrm{L}\right)\end{array}$ & $\begin{array}{l}\text { Hematocrit } \\
(\%)\end{array}$ & $\begin{array}{l}\text { Blood Platelet } \\
\text { Count }\left(10^{9} / \mathrm{L}\right)\end{array}$ & $\begin{array}{l}\text { Plateletcrit } \\
\quad(\%)\end{array}$ & $\begin{array}{l}\text { Mean Platelet } \\
\text { Volume (fL) }\end{array}$ & $\begin{array}{l}\text { Platelet Volume } \\
\text { Distribution } \\
\text { Width (\%) }\end{array}$ & $\begin{array}{l}\text { Platelet-Larger } \\
\text { Cell Ratio (\%) }\end{array}$ \\
\hline Blank & $6.20 \pm 0.57$ & $31.4 \pm 2.51$ & $701 \pm 86.3$ & $0.391 \pm 0.04$ & $5.46 \pm 0.19$ & $4.37 \pm 0.20$ & $6.21 \pm 0.79$ \\
\hline $\begin{array}{c}\text { Metalloproteinase } \\
\text { SP }\end{array}$ & $5.63 \pm 0.24$ * & $30.1 \pm 2.56$ & $613 \pm 61.6^{*}$ & $0.341 \pm 0.02^{* *}$ & $5.41 \pm 0.29$ & $4.36 \pm 0.60$ & $5.39 \pm 1.21$ \\
\hline
\end{tabular}

In the clopidogrel sulfate treated group, red blood cell count, hematocrit, and platelet-larger ratio cell were decreased compared with the blank group. In the metalloproteinase SP treated group, the red blood cell count, the number of platelets and plateletcrit were decreased. All data were expressed as mean $\pm \mathrm{SD} .{ }^{*} p<0.05$ and ${ }^{* *} p<0.01$ compared with the blank group. 

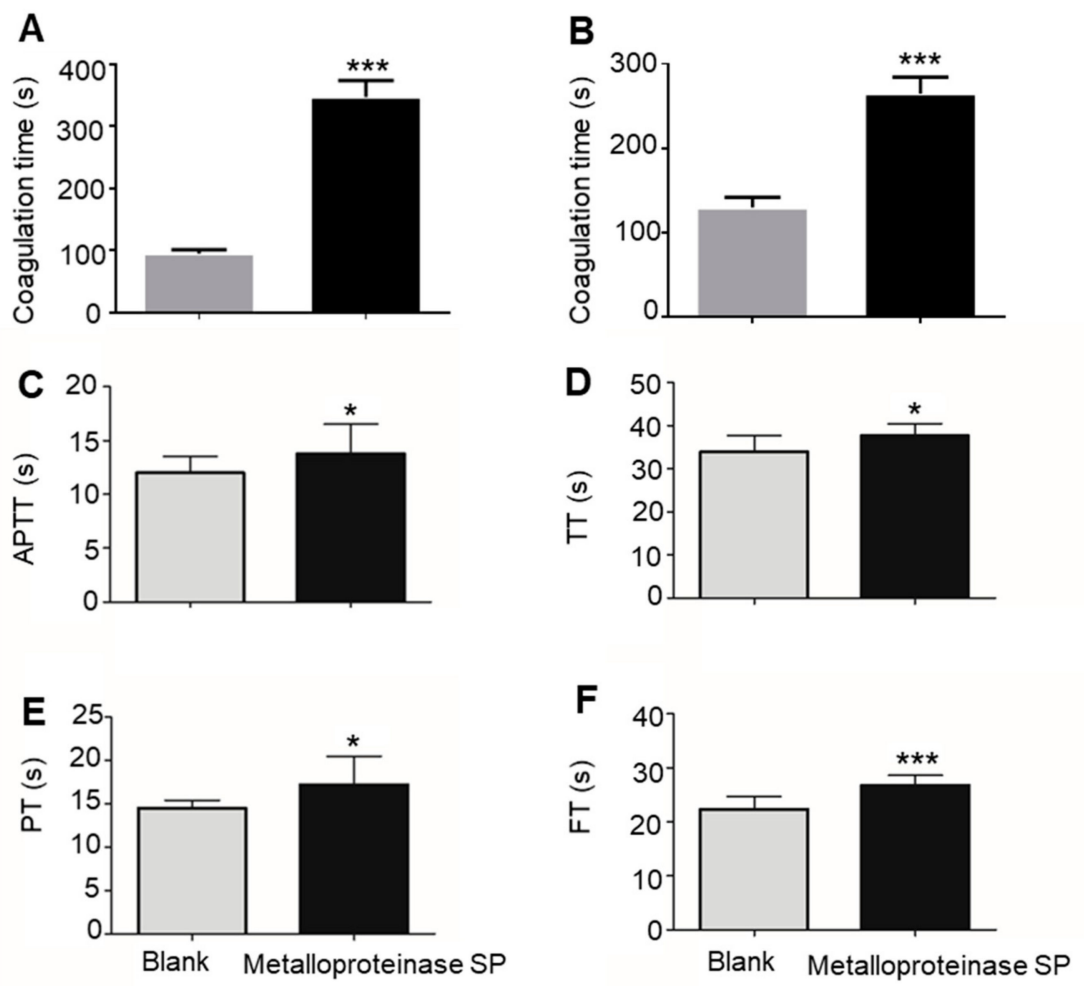

Figure 2. Anticoagulant activity of metalloproteinase SP was evaluated by coagulation time. (A) Blood coagulation time was determined by using the capillary technique. (B) Blood coagulation time was determined by the slide method. (C) Activated partial thromboplastin time (APTT). (D) Thrombin time (TT). (E) Prothrombin time (PT). (F) Fibrinogen time (FT). All data were expressed as mean \pm SD, $n=10, * p<0.05$ and ${ }^{* * *} p<0.01$, compared with the blank group.

\subsubsection{Anti-Thrombotic Activity}

Compared with the blank group, the red blood cell and platelet content in the model group were significantly changed $(* *<0.01)$, indicating the successful establishment of model (Table 3 ). Metalloproteinase SP significantly inhibited acute pulmonary embolism formation induced by ADP (Figure 3A,B). It also inhibited Carrageenan-induced tail thrombus (Figure 3C and Figure S2). CCK-8 assay indicated that metalloproteinase SP did not have cytotoxicity within concentration of $0.5 \mathrm{ug} / \mathrm{mL}$ (Figure S3). Then, metalloproteinase SP activity was evaluated by the classical coagulation assays, thus, activated partial thromboplastin time (APTT), thrombin time (TT), prothrombin time (PT), and fibrinogen time (FT) (Figure 4A-D).

Table 3. Hemodynamic examination of venous blood to check clopidogrel and metalloproteinase SP effects on acute pulmonary embolism mice.

\begin{tabular}{|c|c|c|c|c|c|c|}
\hline & $\begin{array}{l}\text { Red Blood } \\
\text { Cell Count } \\
\left(10^{12} / \mathrm{L}\right)\end{array}$ & $\begin{array}{l}\text { Hematocrit } \\
(\%)\end{array}$ & $\begin{array}{l}\text { Blood Platelet } \\
\text { Count }\left(10^{9} / \mathrm{L}\right)\end{array}$ & $\begin{array}{c}\text { Plateletcrit } \\
(\%)\end{array}$ & $\begin{array}{c}\text { Mean } \\
\text { Platelet } \\
\text { Volume (fL) }\end{array}$ & $\begin{array}{c}\text { Platelet Volume } \\
\text { Distribution } \\
\text { Width }(\%)\end{array}$ \\
\hline Control & $7.54 \pm 0.40$ & $34.6 \pm 1.64$ & $720 \pm 73.5$ & $0.350 \pm 0.04$ & $4.44 \pm 0.65$ & $3.99 \pm 0.34$ \\
\hline Clopidogrel sulfate & $6.93 \pm 0.16^{* *}$ & $31.3 \pm 1.83^{* *}$ & $704 \pm 56.9$ & $0.320 \pm 0.01$ & $4.57 \pm 0.167$ & $3.91 \pm 0.36$ \\
\hline $\begin{array}{l}\text { Metalloproteinase } \\
\text { SP }\end{array}$ & $6.92 \pm 0.19^{* *}$ & $32.0 \pm 1.16^{* *}$ & $640 \pm 64.3^{*}$ & $0.300 \pm 0.03 *$ & $4.70 \pm 0.20$ & $3.84 \pm 0.28$ \\
\hline
\end{tabular}

In the clopidogrel sulfate treated group, red blood cell count and hematocrit were decreased compared with the blank group. In the metalloproteinase SP treated group, the red blood cell level, hematocrit, platelet count, and plateletcrit were decreased compared with blank. All data were expressed as mean \pm SD. ${ }^{*} p<0.05$ and ${ }^{* *} p<0.01$ compared with the blank control group. 

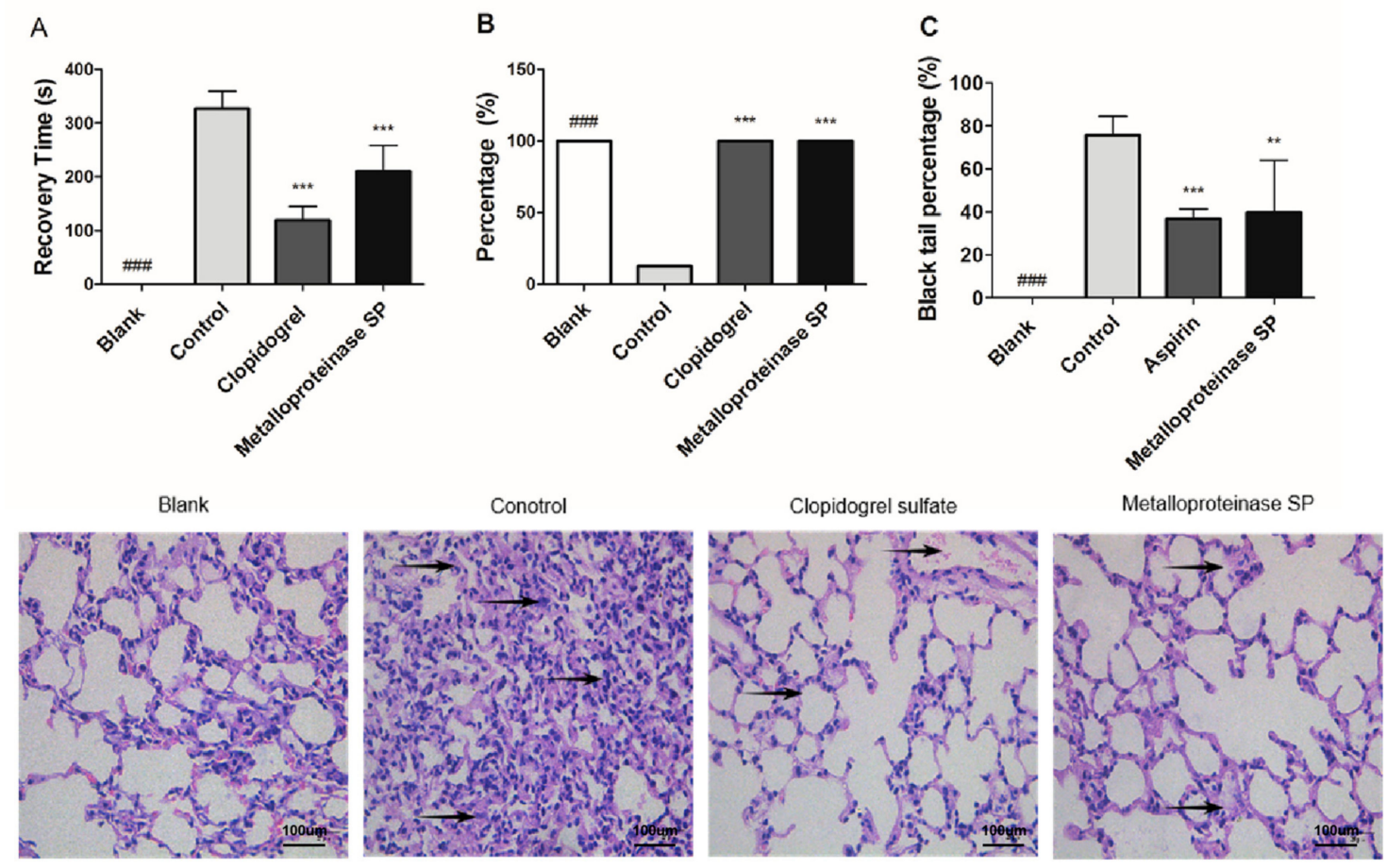

Figure 3. Effects of metalloproteinase SP on thrombosis. (A) Metalloproteinase SP inhibited the tail thrombus induced by the Carrageenan. $(\mathbf{B}, \mathbf{C})$ Metalloproteinase SP inhibited ADP-induced acute pulmonary thrombosis in mice. ADP $(250 \mathrm{mg} / \mathrm{kg})$ was intravenously injected to induce acute pulmonary thrombosis. The time that the mice righting reflex recovery was recorded as the recovery time. The hematoxylin and eosin stained section of the lung tissue shows the one for the control mouse to be dominated by thrombi. Effect of metalloproteinase SP on the ADP-induced formation of acute pulmonary thromboembolism in mice. Compared with the control group, the thrombus of the metalloproteinase SP and the clopidogrel group exhibited significant difference. All data were expressed as mean $\pm \mathrm{SD}$, compared with the control group, ${ }^{* *} p<0.01,{ }^{* * *} p<0.001$ and compared with the blank group ${ }^{\# \# \#} p<0.001$.

\subsubsection{Antiplatelet Aggregation Activity}

In vitro, metalloproteinase SP showed powerful antiplatelet activity by inhibiting the stimulatory effect of ADP, AA, and collagen (Figure $5 \mathrm{~A}-\mathrm{C}$ ). In vivo, it exhibited a dose-dependent inhibition of the ADP-induced aggregation of PRP (Figure 5D-F). However, the inhibitory anti-platelet aggregation activity in vitro was more pronounced than in vivo.

\subsection{Fibrinogenolytic Activity}

In vivo, metalloproteinase SP protein cleaved $\alpha, \beta$, and $\gamma$ chains of fibrinogen, and decomposed the fibrinogen chain sequence in the order, $\alpha>\beta>\gamma$. In addition to degrading the $\alpha, \beta$, and $\gamma$ chains of fibrinogen, metalloproteinase SP also degraded the primary and secondary decomposition products to produce stable small molecular peptides (Figure 6A). Fibrinogen was also used to evaluate the effects of different inhibitors on the activity of metalloproteinase SP. The specific serine protease inhibitors such as benzamidine, butyl boronic acid, trasylol, trypsin, and PMSF were not able to significantly inhibit its enzymatic activity. However, EDTA significantly inhibited its enzymatic activity to a statistically significant level (Figure 6B). Regarding ideal temperature conditions, the enzyme showed high activity at $30-60{ }^{\circ} \mathrm{C}$ (Figure 6C). Metalloproteinase SP showed higher enzymatic activity at neutral $\mathrm{pH}$ values, with optimum catalysis at $\mathrm{pH}$ 6-7 (Figure 6D). 

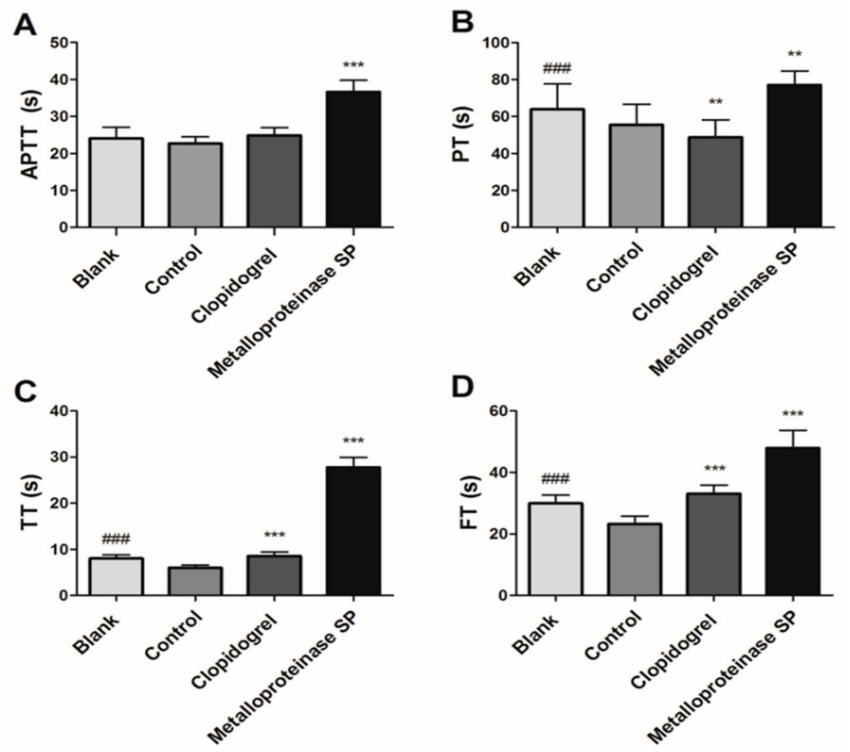

Figure 4. Effects of metalloproteinase SP on acute pulmonary embolism coagulation. Compared with blank group, the activated partial thromboplastin time (APTT), thrombin time (TT), prothrombin time (PT), and fibrinogen time (FT) of the control group exhibited significant difference $\left.{ }^{* * *} p<0.001\right)$. Compared with control group, the metalloproteinase SP group could prolong the APTT, PT, TT, FT. (A) Activated partial thromboplastin time (APTT). (B) Thrombin time (TT). (C) Prothrombin time (PT). (D) Fibrinogen time (FT). All data were expressed as mean $\pm \mathrm{SD}$, compared with the control group, ** $p<0.01^{* * *}, p<0.001$, and compared with the blank group ${ }^{\# \#} p<0.01$.
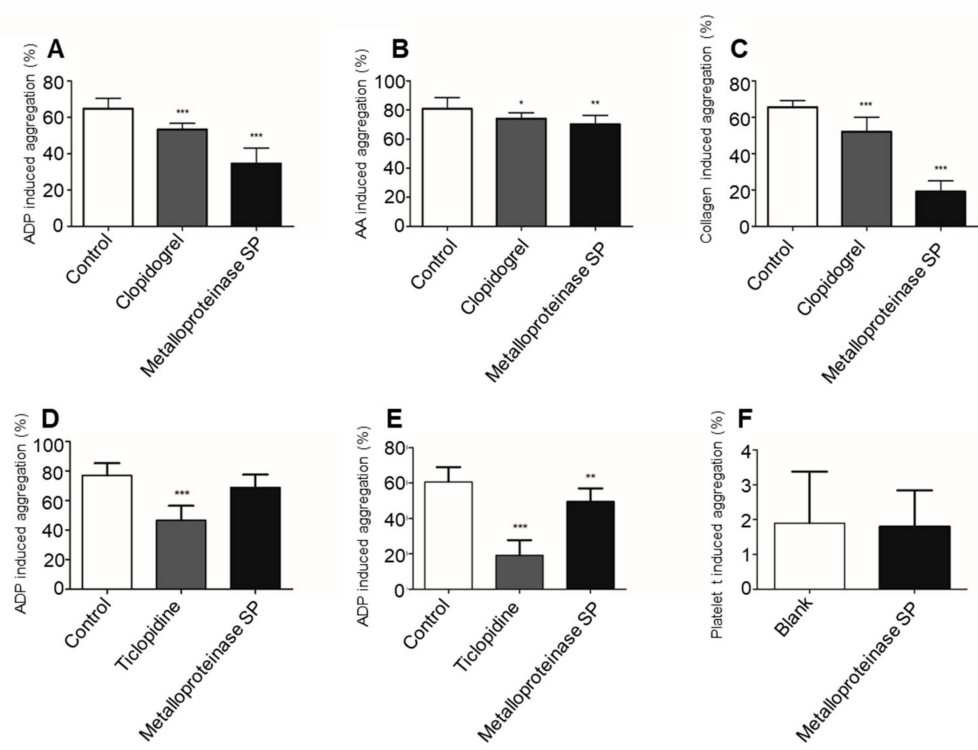

Figure 5. The in vitro and in vivo anti-platelet aggregation activity of metalloproteinase SP. (A) Compared with the blank group, the clopidogrel and the metalloproteinase SP groups specifically inhibited ADP-induced platelet aggregation. Metalloproteinase SP inhibited ADP-induced platelet aggregation with an inhibition rate of $44.28 \%$. (B) Metalloproteinase SP inhibited AA-induced platelet aggregation with an inhibition rate of $13.19 \%$. (C) Metalloproteinase SP inhibited collagen-induced platelet aggregation with an inhibition rate of $71.09 \%$. The anti-platelet aggregation activity of metalloproteinase SP in vitro. (D,E) Metalloproteinase SP exhibited a dose-dependent inhibition of the ADP-induced aggregation of PRP. Compared with blank group, $0.5 \mu \mathrm{g}$ of metalloproteinase SP significantly inhibited ADP-induced platelet aggregation with an inhibition rate of $18.27 \%$. (F) Metalloproteinase SP not exhibited the promoted platelet aggregation activity. All data were expressed as mean $\pm \mathrm{SD}$, compared with the blank control group, ${ }^{*} p<0.05,{ }^{* *} p<0.01,{ }^{* * *} p<0.01$. 

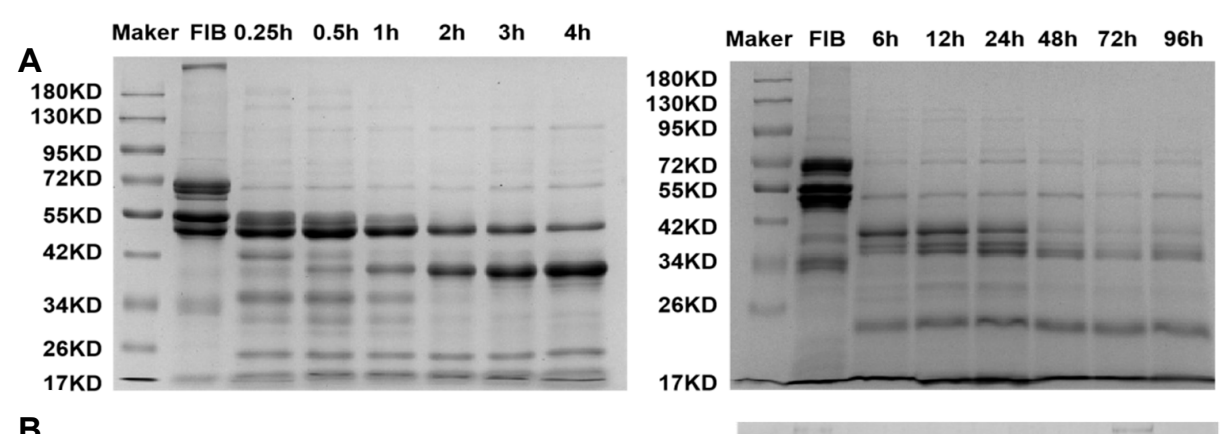

B
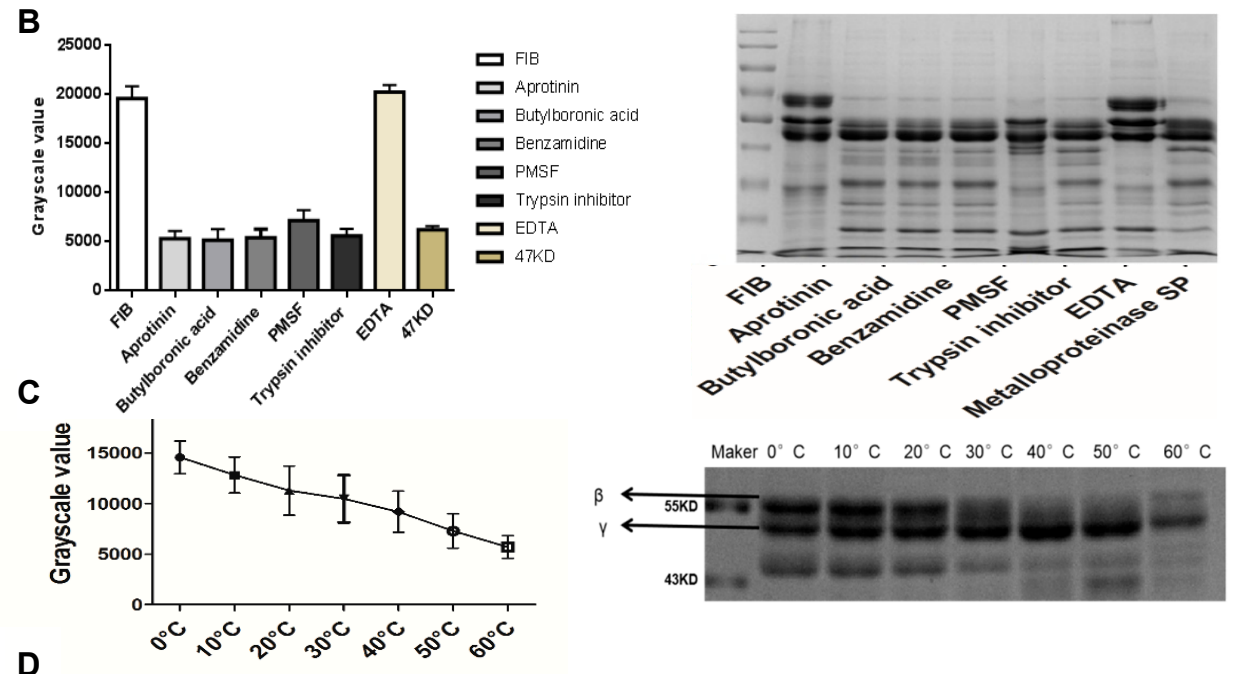

D
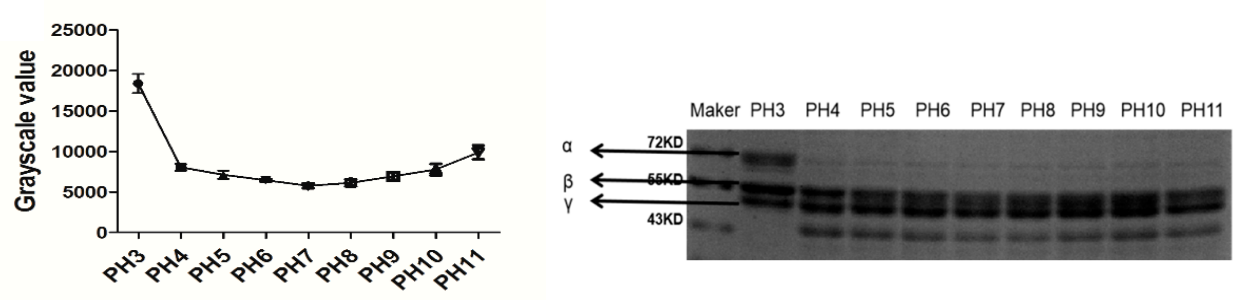

Figure 6. (A) Time-dependent effect of metalloproteinase SP on fibrinogen. Fibrinogenolytic activity was evaluated on $12 \%$ SDS-PAGE after incubation of metalloproteinase SP $(5 \mu \mathrm{g})$ with human fibrinogen at $37^{\circ} \mathrm{C}$ for different time periods. (B) Effects of inhibitors on metalloproteinase SP. Metalloproteinase SP was pre-incubated at $37^{\circ} \mathrm{C}$ for $30 \mathrm{~min}$ at the presence of benzamidine $(5 \mathrm{mM})$, ethylenediaminetetraacetic acid (EDTA, $5 \mathrm{mM})$, butyl boronic acid (20 mM), Trasylol (400 IU), trypsin inhibitor (20 mM), and PMSF (5 mM), respectively, prior to the addition of fibrinogen. (C) Temperature dependent effect of metalloproteinase SP on fibrinogen. Effect of temperature on fibrinogenolytic activity was evaluated on $12 \%$ SDS-PAGE after incubation of metalloproteinase SP (5 $\mu \mathrm{g})$ with human fibrinogen at different temperature for $30 \mathrm{~min}$. (D) The $\mathrm{pH}$-dependent effect of metalloproteinase SP on fibrinogen. Effect of $\mathrm{pH}$ on fibrinogenolytic activity was evaluated on 12\% SDS-PAGE after incubation of metalloproteinase $\mathrm{SP}(5 \mu \mathrm{g})$ with human fibrinogen at different $\mathrm{pH}$ for $30 \mathrm{~min}$. All data were expressed as mean $\pm \mathrm{SD}$.

\subsection{Effects of Snake Venom Monomer on the Chemical Constituents of Acute Pulmonary Embolism}

In this study, the effect of metalloproteinase SP in an acute pulmonary embolism animal model was explored by analyzing metabolomic changes among metalloproteinase SP, model, and blank groups. As shown in the OPLS-DA score plot in both positive and negative ion modes, the three groups could be clearly distinguished (Figure 7A,C). This suggests that metalloproteinase SP exhibited a significant effect on acute pulmonary embolism by changing the anomalous metabolic states. Therefore, the metalloproteinase SP may be able to improve the pathological process of acute pulmonary embolism. The metabolites identified herein are listed in Table 4. 
Table 4. The significantly changed metabolites in mice plasma after treatment with metalloproteinase SP.

\begin{tabular}{|c|c|c|c|c|c|c|c|c|c|c|}
\hline Peak NO & Metabolite Name & Formula & Rt (min) & $\begin{array}{c}\text { Molecular } \\
\text { Weight }\end{array}$ & $p$-Value & FD & Control & $\begin{array}{l}\text { Metalloproteinase } \\
\text { SP }\end{array}$ & (+) MS & (+) MS/MS \\
\hline 1 & $\begin{array}{l}\text { 5-Aminopentanoic } \\
\text { acid }\end{array}$ & $\mathrm{C} 5 \mathrm{H} 11 \mathrm{NO} 2$ & 0.850 & 117.0790 & $* \downarrow$ & 0.7883 & $1.205 \pm 0.241$ & $0.952 \pm 0.179$ & 118.0861 & $\begin{array}{c}118.086,100.075,72.080 \\
57.033,56.049,55.054 \\
44.049,43.018\end{array}$ \\
\hline 2 & o-Tyrosine & C9H11NO3 & 1.100 & 181.0739 & ${ }^{*} \downarrow$ & 0.7218 & $0.857 \pm 0.255$ & $0.615 \pm 0.131$ & 182.0812 & $\begin{array}{c}182.081,165.05,136.075 \\
119.040\end{array}$ \\
\hline 3 & Piperidine & $\mathrm{C} 5 \mathrm{H} 11 \mathrm{~N}$ & 1.467 & 85.0891 & $* * \downarrow$ & 0.7029 & $1.431 \pm 0.445$ & $1.006 \pm 0.295$ & 86.0964 & $\begin{array}{c}86.096,69.070,57.070 \\
56.050,55.054,52.033 \\
44.050,43.054\end{array}$ \\
\hline 4 & L-Isoleucine & $\mathrm{C} 6 \mathrm{H} 13 \mathrm{NO} 2$ & 1.483 & 131.0946 & $* \downarrow$ & 0.7330 & $1.261 \pm 0.316$ & $0.924 \pm 0.138$ & 132.1016 & $\begin{array}{c}132.101,86.096,69.069 \\
44.049,41.038\end{array}$ \\
\hline 5 & L-Phenylalanine & C9H11NO2 & 1.917 & 165.0790 & $* \downarrow$ & 0.8219 & $1.314 \pm 0.249$ & $1.083 \pm 0.237$ & 166.0856 & $\begin{array}{l}\text { 166.086, 149.059, 131.049, } \\
120.080,107.049,103.054\end{array}$ \\
\hline 6 & L-Norleucine & $\mathrm{C} 6 \mathrm{H} 13 \mathrm{NO} 2$ & 2.083 & 131.0946 & $* * \downarrow$ & 0.7168 & $0.860 \pm 0.153$ & $0.616 \pm 0.095$ & 132.1009 & $\begin{array}{l}\text { 132.10, 97.653, 86.695, } \\
69.069,44.048,30.338\end{array}$ \\
\hline 7 & $\begin{array}{c}\text { Palmitoyl } \\
\text { Ethanolamide }\end{array}$ & $\mathrm{C} 18 \mathrm{H} 37 \mathrm{NO} 2$ & 3.767 & 299.2824 & $* * \uparrow$ & 1.3987 & $0.917 \pm 0.208$ & $1.283 \pm 0.183$ & 300.2892 & $\begin{array}{c}300.289,282.279,85.100 \\
83.085,71.085,67.054 \\
62.060,57.069,43.054\end{array}$ \\
\hline 8 & beta-Alanine & $\mathrm{C} 3 \mathrm{H} 7 \mathrm{NO} 2$ & 0.617 & 89.0477 & $* \downarrow$ & 0.7330 & $1.071 \pm 0.195$ & $0.751 \pm 0.110$ & 88.0406 & $\begin{array}{c}88.040,71.013,59.013 \\
53.003,44.997,43.018 \\
42.034,41.002\end{array}$ \\
\hline 9 & L-Tyrosine & C9H11NO3 & 0.900 & 181.0739 & $* \downarrow$ & 0.7772 & $0.795 \pm 0.116$ & $0.618 \pm 0.127$ & 180.0664 & $\begin{array}{c}180.066,163.040,119.050 \\
72.009,93.034,74.024\end{array}$ \\
\hline 10 & Benzyl glycinate & C9H11NO2 & 1.916 & 165.0790 & $* \downarrow$ & 0.8400 & $1.208 \pm 0.269$ & $1.015 \pm 0.174$ & 164.0716 & $164.071,91.055,77.039$ \\
\hline 11 & $\begin{array}{c}\mathrm{p} \text {-Cresol } \\
\text { glucuronide }\end{array}$ & $\mathrm{C} 13 \mathrm{H} 16 \mathrm{O} 7$ & 2.267 & 284.0896 & $* * \downarrow$ & 0.6891 & $0.540 \pm 0.116$ & $0.372 \pm 0.158$ & 283.0818 & $\begin{array}{c}\text { 283.081, 265.073, 175.026, } \\
117.019,107.049,87.008 \\
71.014,43.018\end{array}$ \\
\hline 12 & p-Cresol sulfate & $\mathrm{C} 7 \mathrm{H} 8 \mathrm{O} 4 \mathrm{~S}$ & 2.633 & 188.0143 & $* * \downarrow$ & 0.5838 & $0.714 \pm 0.159$ & $0.417 \pm 0.128$ & 187.0073 & $\begin{array}{l}\text { 187.007, 107.50, } \\
105.334,77.039\end{array}$ \\
\hline 13 & 10-HDoHE & $\mathrm{C} 22 \mathrm{H} 32 \mathrm{O} 3$ & 4.800 & 344.2351 & $* * \downarrow$ & 0.6892 & $0.559 \pm 0.120$ & $0.385 \pm 0.164$ & 343.2274 & $\begin{array}{c}\text { 343.227, 325.210, 281.227, } \\
\text { 189.130, 161.130, 153.092, } \\
137.095,109.102,59.013\end{array}$ \\
\hline 14 & $\begin{array}{c}\text { Octadec-9-enoic } \\
\text { Acid }\end{array}$ & $\mathrm{C} 18 \mathrm{H} 34 \mathrm{O} 2$ & 10.150 & 282.4680 & $* * \uparrow$ & 1.6569 & $1.033 \pm 0.174$ & $1.713 \pm 0.826$ & 281.2478 & $281.248,263.238,59.0139$ \\
\hline
\end{tabular}

Compared to control group, “ $\uparrow$ and $\downarrow$ ” means the relative content of ions which is significantly increased or decreased. ${ }^{*} p<0.05,{ }^{* *} p<0.01$. 


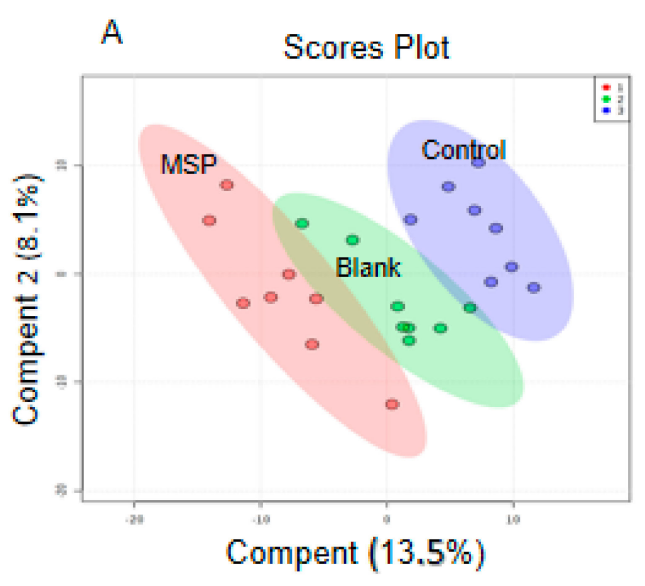

$\mathrm{C}$

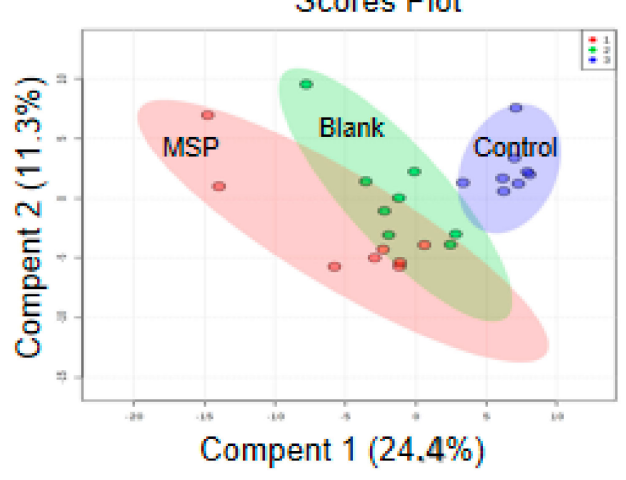

B

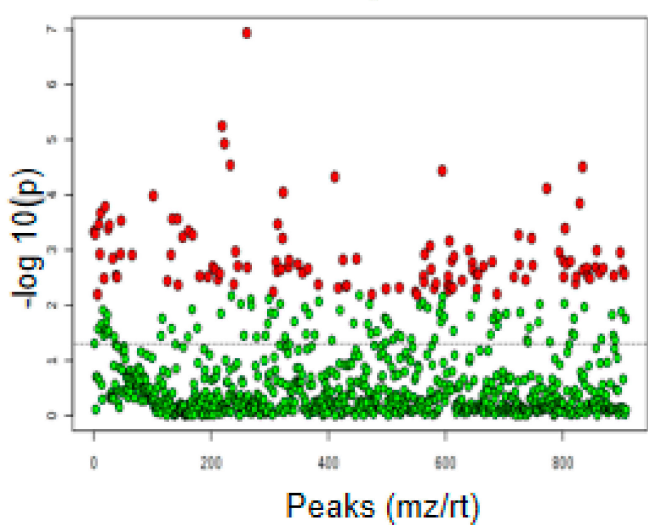

$\mathrm{D}$

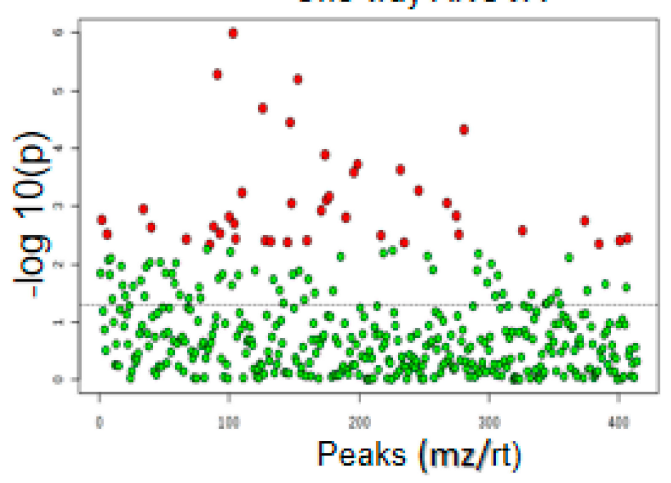

Figure 7. Score plot of plasma metabolomic profiling of three groups mice in positive ion mode (A) and negative ion mode (C). A total of 119 differential ions were screened by "adjusted $p$-value $<0.05$, Fold change $>2$ " in positive ion mode (B). A total of 42 differential ions were screened by "adjusted $p$-value $<0.05, \mathrm{FC}>2$ " in negative ion mode $(\mathbf{D})$.

The potential metabolic pathways and networks were analyzed by Metabo Analyst 4.0. Based on the Met PA analysis of Metabo Analyst 4.0, the related biomarkers primarily participated in the following pathways: tyrosine and tryptophan biosynthesis, phenylalanine metabolism, catecholamine biosynthesis, beta-alanine metabolism, aspartate metabolism, histidine metabolism, propanoate metabolism, pyrimidine metabolism, valine, leucine and isoleucine degradation, and tyrosine metabolism (Figure 8, Table 5).

Table 5. Metabolic pathways and differential metabolites.

\begin{tabular}{cccc}
\hline NO & Pathway & Hits & Metabolites \\
\hline 1 & Phenylalanine, tyrosine and tryptophan biosynthesis & 2 & L-Phenylalanine, L-Tyrosine \\
2 & Phenylalanine metabolism & 2 & L-Phenylalanine, L-Tyrosine \\
3 & Beta-Alanine Metabolism & 1 & Beta-Alanine \\
4 & Aspartate Metabolism & 1 & Beta-Alanine \\
5 & Histidine Metabolism & 1 & Beta-Alanine \\
\hline
\end{tabular}


A

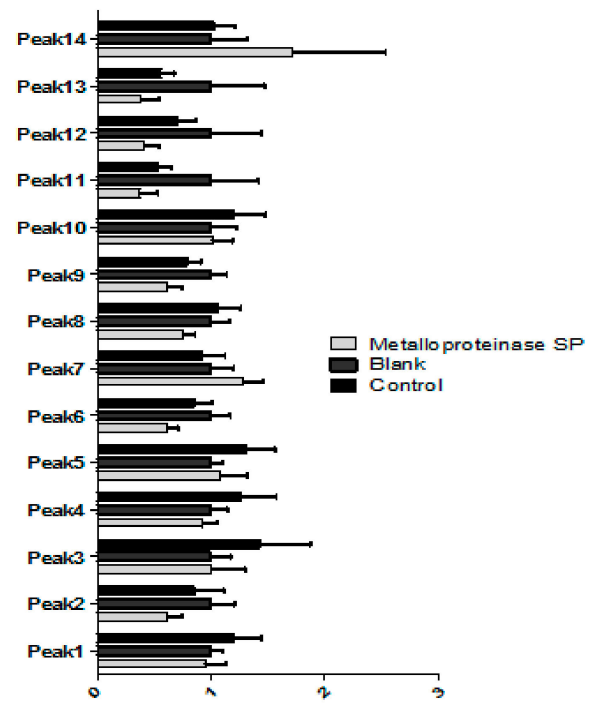

B

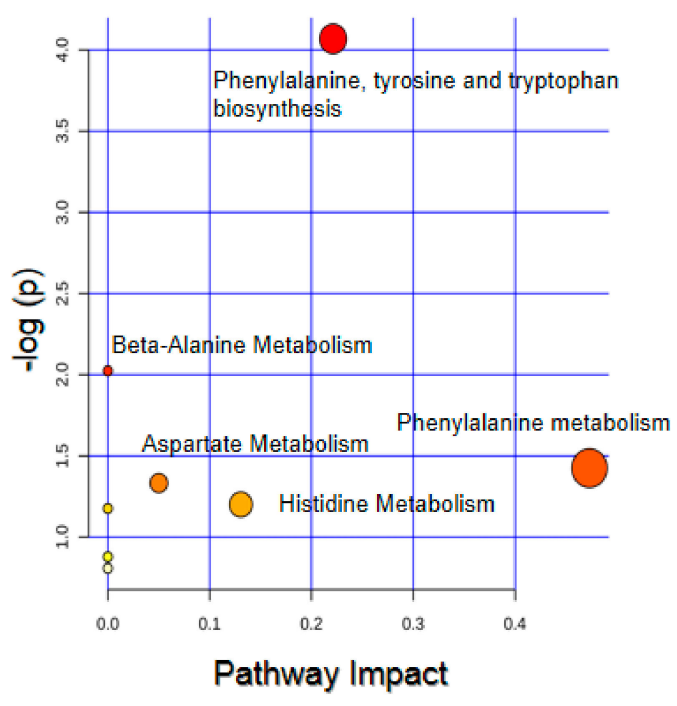

Figure 8. (A) Relative signal intensities for metabolic biomarkers in the blood. (B) Summary of pathway analysis with Metabo Analyst 4.0. Each ordinate in the plot represents a metabolic pathway. The ordinate is the original $p$-value obtained from the pathway analysis, and the abscissa is the influence value of pathways obtained from the topological analysis. The ordinate color and size of each circle was based on $p$-value and pathway impact value, respectively.

\section{Discussion}

The snake venom contains a large number of active proteins, peptides and small molecular weight compounds, which show anticoagulant, procoagulant, antithrombotic, antiplatelet aggregation, Fibrinogenolytic activity, analgesic, and other activities [15-18]. In the past few decades, various snake venom proteins have been extensively studied, and many snake venom proteins have been purified and characterized. Some snake venom preparations have been widely used in clinical settings as hemostatics, anticoagulants, antithrombotics, and thrombolytics. Examples include Ancrod, Batroxobin, and Acutase [18,19].

In the present study, metalloproteinase SP was purified form Agkistrodon acutus venom through ultracentrifugation, molecular exclusion chromatography on Sephadex TM G-75, anion exchange chromatography on DEAE-SphadexA-50, Sephadex TM G-75, and ultrafiltration. The molecular weight of metalloproteinase SP was determined by LC-MS/MS to be $22.9 \mathrm{kDa}$ [20]. Metalloproteinase SP was proven to show anticoagulant, antithrombotic, antiplatelet aggregation, and fibrinogenolytic activities, and improve blood rheology. In vivo and in vitro experiments showed that metalloproteinase SP could cleave $\alpha, \beta$, and $\gamma$ chains of fibrinogen and further reduce fibrinogen content.

Fibrinogen plays a vital role blood coagulation, blood rheology, platelet aggregation, and thrombosis [21,22]. The coagulation process is traditionally classified into extrinsic, intrinsic, and common coagulation. In the common pathway of coagulation, fibrinogen forms the insoluble fibrin network under the stimulation of coagulation factors such as thrombin and FXa, which ultimately constitutes a fibrin clot that stops bleeding [23,24]. Fibrinogen mainly affects platelet aggregation, blood rheology, fibrinogen clot structure, atherosclerosis, plasmin activation, and fibrinogen decomposition (FgDP) to adjust the formation of thrombus [24-28]. Hence, the centrality of fibrinogen in platelet aggregation cannot be overemphasized. Fibrinogen has multiple GPIIb/IIa receptor binding sequences, such as $\gamma 400 \sim 411, \alpha 95 \sim 97$, and $\alpha 572 \sim 574$ [29]. Fibrinogen functions as a bridge of platelet aggregation [29-31]. Moreover, fibrinogen is the most important factor affecting plasma viscosity. Increased plasma fibrinogen levels inevitably result in elevated plasma viscosity and shear stress, as well as endothelial cells and platelets activation. Activation of endothelial cells further promotes the expression or activation of various adhesion molecules and integrins, which leads 
to red blood cells adhesion and platelets aggregation and thrombosis [32-34]. Fibrin also possesses multiple plasminogen binding sites. Fibrinogen was cleaved by metalloproteinase SP to form fibrin, which may be through decomposing the $\alpha, \beta$, and $\gamma$ chain of fibrinogen, to reduce the content of the fibrinogen in the blood. Furthermore, it affected the blood coagulation pathway, prolonged the clotting time, directly inhibited the aggregation of platelets, indirectly regulated blood rheology, and indirectly regulated the formation of thrombus [35-38].

Based on the in vivo and in vitro experiments, the underlying mechanism of metalloproteinase SP on ADP-induced acute pulmonary embolism in mice was further investigated by untargeted mass spectrometry-based metabolomics profiling [39]. Metalloproteinase SP inhibited the formation of acute pulmonary embolism induced by ADP, which may be related to the amino acid metabolism and synthesis, including phenylalanine, tyrosine and tryptophan biosynthesis, phenylalanine metabolism, catecholamine biosynthesis, and eight other metabolic pathways [40,41].

Phenylalanine is one of the essential amino acids in humans that forms tyrosine under the action of phenylalanine hydroxylase in the liver [42,43]. Tyrosine synthesizes certain hormones and neurotransmitters such as dopamine (DA), norepinephrine (NE), epinephrine (E), and melanin in the nervous system and adrenal medulla. Thus, tyrosine plays an important role in regulating energy metabolism and scavenging free radicals [40]. Metalloproteinase SP regulated the biosynthesis of tyrosine and tryptophan, thereby alleviating lipid metabolism disorder and exert indirectly inhibited the formation of thrombus.

The content of catecholamines is closely related to blood coagulation and thrombosis [44]. Excessive levels of catecholamines could result in hypertension and acute myocardial infarction. Catecholamines act on platelet alpha (2)-adrenergic receptors to regulate platelet activation and aggregation, blood coagulation, and thrombosis.

The anticoagulant and antithrombotic activity of metalloproteinase SP may be ascribed to the regulation of histidine metabolism. Histidine is a semi-essential amino acid that is decarboxylated to form histamine under the action of histidine decarboxylase. Histamine exhibits diastolic vasoactive, antihypertensive and anti-inflammatory activities, and regulates a variety of allergic reactions. Histamine is clinically used for angina pectoris, cardiac insufficiency and other diseases [45]. Histamine has a strong vasodilator effect and is associated with a variety of allergic reactions and inflammation. Histidine may indirectly regulate inflammatory factors and inflammatory reaction by regulating the synthesis of histamine, thus inhibiting the formation of thrombus.

Metalloproteinase SP has many pharmacological activities, such as prolonging coagulation time, anti-platelet aggregation, inhibiting thrombosis, and decomposing fibrinogen. Metalloproteinase SP has high affinity with fibrinogen, and its anti-platelet aggregation and inhibition of thrombosis are closely related to its ability to decompose fibrinogen. Studies have shown that fibrinogen decomposition has an important relationship with the activation of fibrinolytic enzymes, and at the same time affects them. The experimental results showed that metalloproteinase SP can rapidly decompose fibrinogen and plays an anti-thrombotic role. However, fibrinogen content that is too low can easily lead to hemorrhage and coagulation disorders. At the same time, metalloproteinase has certain blood toxicity, which may lead to the reduction of platelet count and erythrocyte count. Thus, toxicity and safety of this venome component are needed to be further studied before its application in clinical.

\section{Materials and Methods}

\subsection{Materials}

SPF grade ICR mice (18-22 g) were purchased from the Comparative Medical Center of Yangzhou University (Jiangsu province, China, License No. SYXK (Su) 2018-0019). Sprague-Dawley rats (180-220 g) were purchased from Nanjing Qing long Shan Animal Center (Jiangsu province, China, License No. SYXK (su) 2018-0022). Animals were housed in a room of temperature of $22 \pm 2{ }^{\circ} \mathrm{C}$, relative humidity of $50 \pm 5 \%$, and exposed to $12 \mathrm{~h}$ dark/light cycle. The animals had free access to 
food and drinking water, and were allowed to acclimatize to their new environment for 1 week. The experiments were carried out in accordance with the guidelines and the regulations of the Ethical Committee of the China Pharmaceutical University. The protocols were approved by the Institutional Animal Care and Use Committee of the China Pharmaceutical University. The ethics approval number was AUC-37 (20180329) and the approval date was 29 March 2018.

\subsection{Separation and Purification of Metalloproteinase $S P$}

A total of $1000 \mathrm{mg}$ venom powder was dissolved in $5 \mathrm{mM}$ Tris- $\mathrm{HCl}$ solution (pH 7.4), and then centrifuged at $12,000 \mathrm{r} / \mathrm{min}$ for $15 \mathrm{~min}$ at $4{ }^{\circ} \mathrm{C}$. After centrifugation, the supernatant was collected and loaded on a gel filtration column of Sephadex TM G-75. The transparent supernatant was further analyzed by molecular exclusion chromatography with Sephadex TM G-75 column $(1 \times 100 \mathrm{~cm}$, GE Healthcare, Frankfurt, Germany), which was pre-conditioned with $5 \mathrm{mM}$ Tris- $\mathrm{HCl}$ (pH 7.4). Aliquots separated samples $\left(4 \mathrm{~mL} /\right.$ tube) were collected at a flow rate of $0.5 \mathrm{~mL} / \mathrm{min}$ at $15{ }^{\circ} \mathrm{C}$. The target component was chosen according to its profile on sodium dodecyl sulfate poly-acrylamide gel electrophoresis (SDS-PAGE) and was pooled, lyophilized, and then stored at $-20^{\circ} \mathrm{C}$ for subsequent chromatographic analysis. The target component from Sephadex TM G-75 was solubilized in $4 \mathrm{~mL}$ of $5 \mathrm{mM}$ Tris- $\mathrm{HCl}$ ( $\mathrm{pH} 7.4$ ), and centrifuged at $12,000 \mathrm{r} / \mathrm{min}$ for $15 \mathrm{~min}$ at $4{ }^{\circ} \mathrm{C}$. The supernatant was loaded on the anion exchange chromatography column (DEAE-SphadexA-50, $2 \times 150 \mathrm{~cm}$ GE Healthcare, Germany) previously equilibrated and eluted with $5 \mathrm{mM}$ Tris- $\mathrm{HCl}(\mathrm{pH}$ 7.4). The target proteins were sequentially washed out with $5 \mathrm{mM}$ Tris- $\mathrm{HCl}(\mathrm{pH} 7.4), 0-0.2 \mathrm{M} \mathrm{NaCl}$ in $5 \mathrm{mM}$ Tris- $\mathrm{HCl}$ (pH 7.4), and $0.2 \mathrm{M} \mathrm{NaCl}$ in $5 \mathrm{mM}$ Tris- $\mathrm{HCl}(\mathrm{pH}$ 7.4). The $4 \mathrm{~mL} /$ tube samples were collected at a flow rate of $0.5 \mathrm{~mL} / \mathrm{min}$ at $15^{\circ} \mathrm{C}$. The target component was chosen based on its SDS-PAGE profile and was re-chromatographed after lyophilization. The clear supernatant was subjected to further purification via molecular exclusion chromatography using Sephadex TM G-75 $(1 \times 50 \mathrm{~cm}$, GE Healthcare, Germany), previously equilibrated and eluted with $5 \mathrm{mM}$ Tris- $\mathrm{HCl}$ (pH 7.4). Samples of $3 \mathrm{~mL} /$ tube were collected at a flow rate of $0.5 \mathrm{~mL} / \mathrm{min}$ at $15^{\circ} \mathrm{C}$. The target component was chosen according to its profile on sodium dodecyl sulfate poly-acrylamide gel electrophoresis (SDS-PAGE) and was pooled, lyophilized, and stored at $-20^{\circ} \mathrm{C}$ for further chromatographic analysis.

\subsection{Protein Quantification and Identification}

The protein concentration was determined by the Bradford Protein Concentration Assay Kit (Thermo Fisher Scientific Incorporation, MA, USA), according to the manufacturer's instructions [46]. The purified venome protein was separated by SDS-PAGE and identified by LC-MS/MS and a Uniprot database search (https://www.uniprot.org/uniprot/?query=agkistrodon+acutus\&sort=score).

\subsection{Pharmacological Evaluation of Metalloproteinase SP}

\subsubsection{Anti-Coagulant Activity}

Blood Clotting Assays

Half an hour after metalloproteinase SP intravenous administration via the tail vein, blood samples were collected from the orbital plexus of mice. Afterward, the time for the blood coagulate was recorded. The clotting time was observed when microfibril was visible. The average time of each observation was $20 \mathrm{~s}$. The collected blood samples were also spotted on glass slides and clotting times determined. Clotting was achieved when the fibrin mesh appeared and could be picked by glass dissecting needle $[47,48]$.

\section{Blood Parameters Test}

Half an hour after clopidogrel sulfate and metalloproteinase SP administration via the tail vein, blood samples were collected from the orbital plexus of mice or from abdominal aorta of mice. Both 
venous and arterial blood were anticoagulated by heparin sodium. The anticoagulant whole blood was placed in the automatic blood cell analyzer (RT-7600Vet, Rayto, Shenzhen, China) for detection and analysis within $2 \mathrm{~h}$.

\section{Coagulation Function Test}

One hour after the intravenous administration of test drugs or vehicles, blood samples were harvested from the orbital plexus. An aliquot of $600 \mu \mathrm{L}$ blood was gently mixed with $66 \mu \mathrm{L}$ citrate sodium anticoagulant. The changes of blood corpuscles in whole blood (anticoagulated by citrate sodium) were analyzed using blood cell analyzer RT-7600Vet (Rayto, Shenzhen China). After centrifugation at $3000 \mathrm{rpm} / \mathrm{min}$ for $15 \mathrm{~min}$, the plasma and blood cells were collected and analyzed for four coagulation parameters using the semiautomatic blood coagulation analyzer LG-PABER-I (STEELLEX, Beijing, China) [49-51]. These parameters were: activated partial thromboplastin time (APTT), thrombin time (TT), prothrombin time (PT), and Fibrinogen time (FT). Standard analytical protocols were closely followed for all determinations.

\subsubsection{Anti-Thrombotic Activity}

The anti-thrombotic effect of metalloproteinase SP was evaluated using two thrombosis pathological models $[52,53]$.

ADP-Induced Acute Pulmonary Thrombosis in Mice

After metalloproteinase SP and clopidogrel treatment for $1 \mathrm{~h}$, the ADP solution $(250 \mathrm{mg} / \mathrm{kg})$ was intravenously administered to induce acute pulmonary embolism, which could probably cause the paralysis or unpredicted death of mice. The recovery time of the mice was then recorded. After establishment of the model, the whole blood cell changes were assayed and coagulation parameters determined as earlier mentioned.

Half an hour after metalloproteinase SP intravenous administration via the tail vein, blood samples were collected from the orbital plexus of mice of mice. Both venous and arterial blood were anticoagulated by heparin sodium. The anticoagulant whole blood was placed in the automatic blood cell analyzer (RT-7600Vet, Rayto, Shenzhen, China) for detection and analysis within $2 \mathrm{~h}$.

Carrageenan-Induced Tail Thrombosis in Mice

One hour after intravenous administration of metalloproteinase SP and aspirin in each group, Carrageenan solution $(20 \mathrm{mg} / \mathrm{kg})$ was intraperitoneally injected to induce tail thrombosis. The mice were then placed in environmentally-friendly cages for $12 \mathrm{~h}$ and their tail lengths recorded.

\subsubsection{Antiplatelet Aggregation Activity}

In Vivo Antiplatelet Aggregation Assay

After $60 \mathrm{~min}$ of administration in each group, the rats were anaesthetized with $50 \mathrm{mg} / \mathrm{kg}$ chloral hydrate via abdominal injection. Blood samples were collected from abdominal aorta via cannulation. An aliquot of $8 \mathrm{~mL}$ blood was gently mixed with $880 \mu \mathrm{L}$ citrate sodium anticoagulant $(3.8 \%, v / v)$. Afterward, platelet-rich plasma (PRP) was obtained after centrifugation at $1000 \mathrm{rpm} / \mathrm{min}$ for $10 \mathrm{~min}$. The residue was further centrifuged at $3000 \mathrm{rpm} / \mathrm{min}$ for $10 \mathrm{~min}$ to get platelet poor plasma (PPP). Prior to the antiplatelet aggregation assay, both PRP and PPP were incubated at $37^{\circ} \mathrm{C}$. An aliquot of $250 \mu \mathrm{L}$ PPP was added into the measuring cup to calibrate the baseline. Thereafter, $225 \mu \mathrm{L}$ of PRP was added and platelet aggregation stimulated with $25 \mu \mathrm{L}$ different stimulants; thus, ADP $(150 \mu \mathrm{M})$, AA $(1 \mathrm{mg} / \mathrm{mL})$, Collagen $(50 \mu \mathrm{g} / \mathrm{mL})$. Platelet aggregation was measured by aggregometer (AggRAM, Helena, USA), and the maximal aggregation rate was recorded within 5 min [54]. 
In Vitro Antiplatelet Aggregation Activity

The blank PRP plasma was harvested from control rats. Metalloproteinase SP ( $1 \mu \mathrm{g}, 5 \mu \mathrm{g})$ was pre-incubated with $225 \mu \mathrm{L}$ PRP at $37^{\circ} \mathrm{C}$ for $5 \mathrm{~min}$, and then stimulated with $25 \mu \mathrm{L}$ different aggregating agents at the following final concentrations (ADP $15 \mu \mathrm{M}$ ). Platelet aggregation was assayed by a platelet aggregation instrument (AggRAM, Helena, TX, USA), and the maximum aggregation rate recorded in $5 \mathrm{~min} .225 \mathrm{uL}$ aliquot of PRP was measured into each cuvette and stimulated with metalloproteinase SP $25 \mathrm{uL}(1 \mu \mathrm{g}, 5 \mu \mathrm{g})$. Platelet aggregation was assayed by a platelet aggregation instrument, and the maximum aggregation rate recorded in $5 \mathrm{~min}$ [53].

\subsubsection{Fibrinogenolytic Activity}

Human fibrinogen $(8 \mathrm{mg} / \mathrm{mL})$ was incubated with $5 \mu \mathrm{g}$ metalloproteinase SP at $37^{\circ} \mathrm{C}$ for $0.25 \mathrm{~h}$, $0.5 \mathrm{~h}, 1 \mathrm{~h}, 2 \mathrm{~h}, 3 \mathrm{~h}, 4 \mathrm{~h}, 6 \mathrm{~h}, 12 \mathrm{~h}, 24 \mathrm{~h}, 48 \mathrm{~h}, 72 \mathrm{~h}$, and $96 \mathrm{~h}$ [53]. Afterward, the samples mixed with loading buffer solution were heated at $100{ }^{\circ} \mathrm{C}$ for $10 \mathrm{~min}$. All samples were transferred to SDS-PAGE system for fibrinogen degradation analysis.

Effect of Temperature and $\mathrm{pH}$ on Metalloproteinase SP Activity

Human fibrinogen $(8 \mathrm{mg} / \mathrm{mL})$ was incubated with $5 \mu \mathrm{g}$ metalloproteinase SP at $0{ }^{\circ} \mathrm{C}, 10{ }^{\circ} \mathrm{C}, 20^{\circ} \mathrm{C}$, $30{ }^{\circ} \mathrm{C}, 40^{\circ} \mathrm{C}, 50^{\circ} \mathrm{C}$, and $60^{\circ} \mathrm{C}$ for $30 \mathrm{~min}$ [55]. Additionally, $5 \mu \mathrm{g}$ metalloproteinase SP was incubated with buffer solutions of different $\mathrm{pH}(\mathrm{pH} 3,4,5,6,7,8,9,10,11)$ at $37^{\circ} \mathrm{C}$ for $30 \mathrm{~min}$, and subsequently incubated with human fibrinogen $(8 \mathrm{mg} / \mathrm{mL})$ at $37^{\circ} \mathrm{C}$ for another $30 \mathrm{~min}$. All samples were subjected to SDS-PAGE to investigate the effect of temperature and $\mathrm{pH}$ on metalloproteinase SP activity.

Effects of Serine Protease and Metalloproteinase Inhibitors on Metalloproteinase SP Activity

Different inhibitors, benzamidine ( $5 \mathrm{mM})$, ethylenediaminetetraacetic acid (EDTA, $5 \mathrm{mM})$, butyl boronic acid (20 mM), Trasylol (400 IU), trypsin inhibitor ( $20 \mathrm{mM})$, and PMSF (5 mM) were incubated with $5 \mu \mathrm{g}$ metalloproteinase $\mathrm{SP}$ at $37^{\circ} \mathrm{C}$ for $30 \mathrm{~min}$ [54]. The samples were further incubated with human fibrinogen at $37^{\circ} \mathrm{C}$ for $30 \mathrm{~min}$. All samples were analyzed by SDS-PAGE to evaluate the effect of inhibitors on metalloproteinase SP activity.

\subsection{Effects of Snake Venom Monomer on the Chemical Constituents of Acute Pulmonary Embolism Based on UHPLC-Q/TOF-MS Non-Targeted Metabolomics}

An aliquot of $150 \mu \mathrm{L}$ of methanol/acetonitrile (3:1) solution (containing $0.4 \mu \mathrm{g} / \mathrm{mL}$ L-2-chloropheylaanine and $10 \mu \mathrm{g} / \mathrm{mL}$ ketoprofen as the internal standard for the ESI+ and ESImodes respectively) was added to $50 \mu \mathrm{L}$ plasma followed by vigorous vortex-mixing for $30 \mathrm{~s}$. The mixture was centrifuged at $13,000 \mathrm{r} / \mathrm{min}$ at $4^{\circ} \mathrm{C}$ for $10 \mathrm{~min}$ to precipitate protein. The supernatant $(150 \mu \mathrm{L})$ was divided into two portions and dried under a gentle stream of nitrogen gas at room temperature. One of the samples was reconstituted with $75 \mu \mathrm{L}$ of $50 \%$ aqueous acetonitrile for ultra-performance liquid chromatography with quadrupole time-of-flight mass spectrometry (UPLC-Q-TOF-MS) analysis in positive mode while the other was for negative mode. The quality control (QC) samples were prepared to improve the data quality for metabolic profiling.

\subsubsection{UHPLC/Q-TOF MS Analysis}

Chromatographic evaluations were performed with an Agilent 1290 series (Agilent Corp, Santa Clara, CA, USA) HPLC system equipped with a binary pump, degasser, an autosampler, and a temperature-controlled column compartment. Chromatographic separations were achieved on an UPLC BEH C18 column $(1.8 \mu \mathrm{m}, 2.1 \mathrm{~mm} \times 100 \mathrm{~mm}$, Waters, Ireland) [25]. Mobile phase A was 0.1\% formic acid aqueous solution and B was $0.1 \%$ formic acid-acetonitrile solution for the positive ion mode. Mobile phase A was $10 \mathrm{mM}$ ammonium acetate solution and B was $10 \mathrm{mM}$ ammonium acetate acetonitrile solution for the negative ion mode. This mobile phase system was run in a gradient elution 
program as follows: $90-99 \% \mathrm{~A}$, at $0-1 \mathrm{~min} ; 30-90 \% \mathrm{~A}$, at $1-3 \mathrm{~min} ; 15-30 \% \mathrm{~A}$, at $3-8 \mathrm{~min} ; 0-15 \% \mathrm{~A}$, at 8-9 $\mathrm{min} ; 0 \% \mathrm{~A}$, at $9-10 \mathrm{~min}$. The post-run time was $5 \mathrm{~min}$. The oven temperature was set at $30{ }^{\circ} \mathrm{C}$, the injection volume was $10 \mu \mathrm{L}$ and the flow rate was $0.4 \mathrm{~mL} / \mathrm{min}$.

Separated components were detected by Agilent 6545A Q/TOF mass spectrometer (Agilent Corp, Santa Clara, CA, USA) equipped with an ESI interface. The operating parameters were as follows: drying $\mathrm{N}_{2}$ gas flow rate, $8 \mathrm{~L} / \mathrm{min}$; temperature, $320^{\circ} \mathrm{C}$; nebulizer, 35 psig; capillary, $3000 \mathrm{~V}$; skimmer, $65 \mathrm{~V}$; OCT RFV, $750 \mathrm{~V}$; fragmentor $100 \mathrm{~V}$. The reference masses 254.2806 (ketoprofen) and 299.75 (L-Phenylalanine) were used for internal mass calibration during the runs in the positive and negative ion modes. At the scan rate of 1.50 spectra/s using fixed collision energies $(0.00,10.00,20.00,40.00 \mathrm{~V})$ MS/MS data were acquired with isolation width MS/MS medium ( 4 amu).

\subsubsection{Data Processing and Identification of Differential Metabolites}

LC-MS raw data files were converted to $\mathrm{m} / \mathrm{z}$ Data format using DA reprocessor (Agilent Corp., Santa Clara, CA, USA). Peak finding, filtering, and alignment were subsequently carried out using open-source R-Package XCMS [25]. Metabo Analyst 4.0 (https://www.metaboanalyst.ca/) was then employed for the analysis of the data. The use of Metabo Analyst 4.0 can be broadly categorized into three major activities: (1) missing value processing, (2) data filtering, and (3) data normalization (i.e., sample normalization, data transformation, and data scaling) [55].

Using Metabo Analyst 4.0 unsupervised principal component analysis (PCA), a general picture of the relationship that exists among the data matrix was obtained. Thereafter, the supervised orthogonal partial least-squares discrimination analysis (OPLS-DA) was carried out to examine the metabolite differences between the treatment, blank, and model groups. The inclusion criterion of the metabolites was that, the fold change between the groups compared should be greater than 1.2 and $p$-value $<0.05$ (one-way ANOVA).

Metabolites that met this criterion were considered as the differential metabolites. In the identification of the biomarkers, the following databases were used: METLIN (http://metlin.scripps. edu/), HMDB database (http://www.hmdb.ca/), Metabo Analyst4.0 (https://www.metaboanalyst.ca/), SMPDB (http://www.smpdb.ca/) and KEGG (http://www.genome.jp/kegg/) [55,56]

\subsection{Statistical Analysis}

Functional and enzymatic activities were assessed by two individual experiments in triplicate. All data were expressed as mean \pm SD. The significance of differences was analyzed by one-way ANOVA followed by the Bonferroni correction. A value of $p<0.05$ was considered statistically significant.

\section{Conclusions}

In this study, a novel metalloproteinase SP was isolated from Agkistrodon venom. In vivo, the metalloproteinase SP protein showed anticoagulant, antithrombotic, and antiplatelet aggregation activities and changed blood rheology. In vitro, metalloproteinase SP strongly inhibited platelet aggregation and cleaved the $\alpha, \beta$, and $\gamma$ chains of fibrinogen, but its activity was obviously affected by temperature or $\mathrm{pH}$ and could be reversed by EDTA. Finally, this study successfully built a mice model with acute pulmonary embolism to explore the antithrombotic mechanism of metalloproteinase SP. Assisted by LC-MS-Q-TOF-MS analysis, 14 representative biomarkers were identified, involving in phenylalanine, tyrosine and tryptophan biosynthesis, phenylalanine metabolism, catecholamine biosynthesis, and eight other metabolic pathways. All these findings indicated that metalloproteinase SP may affect blood coagulation and thrombus formation by decomposing fibrinogen and anti-platelet aggregation

Supplementary Materials: Supplementary Materials can be found at http://www.mdpi.com/1422-0067/20/17/ 4088/s1. 
Author Contributions: J.H., F.H., and X.Y. made the major contributions to this study in the conception, design, drafting part of manuscript, and final revision. H.F. performed statistical analysis of the data and purified protein. All authors read and approved the final manuscript.

Funding: The work was supported by the National Natural Science Foundation of China (No. 6200020055A).

Acknowledgments: We thank Mr Yingchun Tan providing us snake venom. Thanks to the help and support provided by the National Platform for Natural Medicine Active Components and the National Key Laboratory of Pharmacodynamics and the Platform of Chinese Medicine College.

Conflicts of Interest: The authors declare no conflict of interest.

\section{Abbreviations}

$\begin{array}{ll}\text { ANOVA } & \text { Analysis of variance } \\ \text { ADP } & \text { Adenosine diphosphate } \\ \text { AA } & \text { Arachidonic acid } \\ \text { RBC } & \text { Red blood cell } \\ \text { PLT } & \text { Platelet } \\ \text { PCT } & \text { Plateletcrit } \\ \text { HCT } & \text { Hematocrit } \\ \text { MPV } & \text { Mean platelet volume } \\ \text { PDW } & \text { Platelet volume distribution width } \\ \text { P-LCR } & \text { Platelet -larger cell ratio }\end{array}$

\section{References}

1. Raskob, G.E.; Angchaisuksiri, P.; Blanco, A.N.; Buller, H.; Gallus, A.; Hunt, B.J.; Hylek, E.M.; Kakkar, A.; Konstantinides, S.V.; McCumber, M. Thrombosis: A major contributor to global disease burden. Thromb. Res. 2014, 134, 931-938. [CrossRef] [PubMed]

2. Nieswandt, B.; Kleinschnitz, C.; Stoll, G. Ischaemic stroke: A thrombo-inflammatory disease. J. Physiol. 2011, 589, 4115-4123. [CrossRef] [PubMed]

3. Ortiz-Muñoz, G.; Mallavia, B.; Bins, A.; Headley, M.; Krummel, M.F.; Looney, M.R. Aspirin-triggered 15-epi-lipoxin A 4 regulates neutrophil-platelet aggregation and attenuates acute lung injury in mice. Blood 2014, 124, 2625-2635. [CrossRef]

4. Fry, B.G.; Roelants, K.; Champagne, D.E.; Scheib, H.; Tyndall, J.D.; King, G.F.; Nevalainen, T.J.; Norman, J.A.; Lewis, R.J.; Norton, R.S.; et al. The toxicogenomic multiverse: Convergent recruitment of proteins into animal venoms. Annu. Rev. Genom. Hum. G. 2009, 10, 483-511. [CrossRef]

5. Huang, Q.; Yang, Q.D.; Tan, X.L.; Feng, J.; Tang, T.; Xia, J.; Zhang, L.; Huang, L.; Bai, Y.P.; Liu, Y.H. Absence of association between atherosclerotic cerebral infarction and TNFSF4/TNFRSF4 single nucleotide polymorphisms rs1234313, rs1234314 and rs17568 in a Chinese population. J. Int. Med. Res. 2014, 42, 436-443. [CrossRef] [PubMed]

6. Mackessy, S.P. Thrombin-like enzymes in snake venoms. In Toxins and Hemostasis, 2nd ed.; Kini, R., Clemetson, K., Eds.; Springer: Dordrecht, Netherlands, 2010; Volume 39, pp. 2-6.

7. Dempfle, C.E.; Argiriou, S.; Kucher, K.; Müller-Peltzer, H.; Rübsamen, K.; Heene, D.L. Analysis of fibrin formation and proteolysis during intravenous administration of ancrod. Blood 2000, 96, 2793-2802.

8. Bocian, A.; Urbanik, M.; Hus, K.; Łyskowski, A.; Petrilla, V.; Andrejčáková, Z.; Petrillová, M.; Legáth, J. Proteomic analyses of Agkistrodon contortrix venom using 2D electrophoresis and MS techniques. Toxins 2016, 8, 372. [CrossRef] [PubMed]

9. Lomonte, B.; Tsai, W.C.; Ureña-Diaz, J.M.; Sanz, L.; Mora-Obando, D.; Sánchez, E.E.; Fry, B.G.; Gutiérrez, J.M.; Gibbs, H.L.; Sovic, M.G.; et al. Venomics of new world pit vipers: Genus-wide comparisons of venom proteomes across Agkistrodon. J. Proteomics 2014, 96, 103-116. [CrossRef] [PubMed]

10. Tang, S.S.; Wang, X.H.; Zhang, J.H.; Tang, B.S.; Qian, L.; Li, P.Y.; Luo, L.W. Biochemical properties and comparative pharmacology of a coagulant from Deinagkistrodon acutus snake venom. Eur. J. Pharm. Sci. 2013, 49, 90-98. [CrossRef] [PubMed] 
11. Ding, B.; Xu, Z.; Qian, C.; Jiang, F.; Ding, X.; Ruan, Y.; Ding, Z.; Fan, Y. Antiplatelet aggregation and antithrombosis efficiency of peptides in the snake venom of Deinagkistrodon acutusr, isolation, identification, and evaluation. Evid-Based Compl. Alt. 2015, 5, 1-6.

12. Ming, X. A novel direct factor Xa inhibitory peptide with anti-platelet aggregation activity from Agkistrodon acutus venom hydrolysates. Sci. Rep. 2015, 5, 10846.

13. Zeng, F.; Shen, B.; Zhu, Z.; Zhang, P.; Ji, Y.; Niu, L.; Li, X.; Teng, M. Crystal structure and activating effect on RyRs of AhV_TL-I, a glycosylated thrombin-like enzyme from Agkistrodon halys snake venom. Arch. Toxicol. 2013, 87, 535-545. [CrossRef] [PubMed]

14. Castro, H.C.; Zingali, R.B.; Albuquerque, M.G.; Pujol-Luz, M.; Rodrigues, C.R. Snake venom thrombin-like enzymes: From reptilase to now. Cell. Mol. Life Sci. 2004, 61, 843-856. [CrossRef] [PubMed]

15. Ge, Y.H.; Chen, Y.Y.; Zhou, G.S.; Liu, X.; Tang, Y.P.; Liu, R.; Liu, P.; Li, N.; Yang, J.; Wang, J.; et al. Novel antithrombotic protease from marine worm sipunculus nudus. Int. J. Mol. Sci. 2018, 19, 3023. [CrossRef] [PubMed]

16. Kini, M.R. Anticoagulant proteins from snake venoms: Structure, function and mechanism. Biochem. J. 2006, 397, 377-387. [CrossRef]

17. Suntravat, M.; Nuchprayoon, I.; Pérez, J.C. Comparative study of anticoagulant and procoagulant properties of 28 snake venoms from families Elapidae, Viperidae, and purified Russell's viper venom-factor $\mathrm{X}$ activator (RVV-X). Toxicon 2010, 56, 544-553. [CrossRef]

18. Depta, J.P.; Bhatt, D.L. New approaches to inhibiting platelets and coagulation. Annu. Rev. Pharmacol. 2015, 55, 373-397. [CrossRef] [PubMed]

19. Koh, D.C.I.; Armugam, A.; Jeyaseelan, K. Snake venom components and their applications in biomedicine. Cell Mol. Life Sci. 2006, 63, 3030-3041. [CrossRef] [PubMed]

20. Niall, H.D. Automated edman degradation: The protein sequenator. Method Enzymol. 1973, 27, $942-1010$.

21. Breen, P. Basics of coagulation pathways. Int. Anesthesiol. Clin. 2004, 42, 1-9. [CrossRef]

22. Corte, A.L.C.L.; Philippou, H.; Ariëns, R.A.S. Role of fibrin structure in thrombosis and vascular disease. Adv. Protein Chem. Str. 2011, 75-127.

23. Chernysh, I.N.; Nagaswami, C.; Weisel, J.W. Visualization and identification of the structures formed during early stages of fibrin polymerization. Blood 2011, 117, 4609-4614. [CrossRef] [PubMed]

24. Lowe, G.D.; Lee, A.J.; Rumley, A.; Price, J.F.; Fowkes, F.G. Blood viscosity and risk of cardiovascular events: The Edinburgh Artery Study. Brit. J. Haematol. 2015, 96, 168-173. [CrossRef]

25. Uitte de Willige, S.; de Visser, M.C.; Houwing-Duistermaat, J.J.; Rosendaal, F.R.; Vos, H.L.; Bertina, R.M. Genetic variation in the fibrinogen gamma gene increases the risk for deep venous thrombosis by reducing plasma fibrinogen gamma' levels. Blood 2005, 106, 4176-4183. [CrossRef] [PubMed]

26. Hacioglu, G.; Yalcin, O.; Bor-Kucukatay, M.; Ozkaya, G.; Baskurt, O.K. Red blood cell rheological properties in various rat hypertension models. Clin. Hemorheol. Micro. 2002, 26, 27-32.

27. Bennett, J.S. Platelet-fibrinogen interactions. Ann. N. Y. Acad. Sci. 2010, 936, 340-354. [CrossRef]

28. Weisel, J.W. The mechanical properties of fibrin for basic scientists and clinicians. Biophys. Chem. 2004, 112, 267-276. [CrossRef] [PubMed]

29. Collet, J.P.; Allali, Y.; Lesty, C.; Tanguy, M.L.; Silvain, J.; Ankri, A.; Blanchet, B.; Dumaine, R.; Gianetti, J.; Payot, L.; et al. Altered fibrin architecture is associated with hypofibrinolysis and premature coronary atherothrombosis. Arterioscl. Throm. Vas. 2006, 26, 2567-2573. [CrossRef]

30. Collet, J.P.; Allali, Y.; Lesty, C.; Tanguy, M.L.; Silvain, J.; Ankri, A.; Blanchet, B.; Dumaine, R.; Gianetti, J.; Payot, L.; et al. Fibrinogen Hershey IV: A novel dysfibrinogen with a gammaV411I mutation in the integrin alpha(IIb)beta(3) binding site. J. Thromb. Haemost. 2008, 99, 1008-1012.

31. Goncalves, I.I.; Hughan, S.C.; Schoenwaelder, S.M.; Yap, C.L.; Yuan, Y.; Jackson, S.P. Integrin alpha IIb beta 3-dependent calcium signals regulate platelet-fibrinogen interactions under flow involvement of phospholipase C gamma 2. J. Biol. Chem. 2003, 278, 34812. [CrossRef] [PubMed]

32. Wolberg, A.S.; Gabriel, D.A.; Hoffman, M. Analyzing fibrin clot structure using a microplate reader. Blood Coagul Fibrin. 2002, 13, 533-539. [CrossRef]

33. Mannila, M.N.; Lovely, R.S.; Kazmierczak, S.C.; Eriksson, P.; Samnegård, A.; Farrell, D.H.; Hamsten, A.; Silveira, A. Elevated plasma fibrinogen gamma' concentration is associated with myocardial infarction: Effects of variation in fibrinogen genes and environmental factors. J. Thromb. Haemost. 2010, 5, 766-773. [CrossRef] [PubMed] 
34. Lowe, G.D. Blood viscosity and cardiovascular disease. J. Thromb. Haemost. 1992, 67, 494-498. [CrossRef]

35. Koenig, W.; Ernst, E. The possible role of hemorheology in atherothrombogenesis. Atherosclerosis 1992, 94, 93-107. [CrossRef]

36. Fredenburgh, J.C.; Nesheim, M.E. Lys-plasminogen is a significant intermediate in the activation of Glu-plasminogen during fibrinolysis in vitro. J. Biol. Chem. 1992, 267, 26150-26156. [PubMed]

37. Hsiao, G.; Shen, M.Y.; Lin, K.H.; Chou, C.Y.; Tzu, N.H.; Lin, C.H.; Chou, D.S.; Chen, T.F.; Sheu, J.R. Inhibitory activity of kinetin on free radical formation of activated platelets in vitro and on thrombus formation in vivo. Eur. J. Pharmacol. 2003, 465, 281-287. [CrossRef]

38. Chung, T.; Connor, D.; Joseph, J.; Emmett, L.; Mansberg, R.; Peters, M.; Ma, D.; Kritharides, L. Platelet activation in acute pulmonary embolism. J. Thromb. Haemost. 2007, 5, 918-924. [CrossRef] [PubMed]

39. Chen, H.; Miao, H.; Feng, Y.L.; Zhao, Y.Y.; Lin, R.C. Metabolomics in dyslipidemia. Adv. Clin. Chem. 2014, 66, 101-119. [PubMed]

40. Bujak, R.; García-Álvarez, A.; Rupérez, F.J.; Nuño-Ayala, M.; García, A.; Ruiz-Cabello, J.; Fuster, V.; Ibáñez, B.; Barbas, C. Metabolomics reveals metabolite changes in acute pulmonary embolism. J. Proteome Res. 2014, 13, 805-816. [CrossRef] [PubMed]

41. Zeleznik, O.A.; Poole, E.M.; Lindstrom, S.; Kraft, P.; Van, H.V.A.; Lasky-Su, J.A.; Harrington, L.B.; Hagan, K.; Kim, J.; Parry, B.A.; et al. Metabolomic analysis of 92 pulmonary embolism patients from a nested case-control study identifies metabolites associated with adverse clinical outcomes. J. Thromb. Haemost. 2017, 16, 500-507. [CrossRef] [PubMed]

42. Alkaitis, M.S.; Ackerman, H.C. Tetrahydrobiopterin supplementation improves phenylalanine metabolism in a murine model of severe malaria. ACS Infect. Dis. 2016, 2, 827-838. [CrossRef] [PubMed]

43. Wu, X.; Zhao, C.; Zhang, A.; Zhang, J.; Wang, X.; Sun, X.; Sun, Z.; Wang, X. High-throughput metabolomics used to identify potential therapeutic targets of Guizhi Fuling Wan against endometriosis of cold coagulation and blood stasis. RSC Adv. 2018, 8, 19238-19250. [CrossRef]

44. Schwencke, C.; Schmeisser, A.; Weinbrenner, C.; Braun-Dullaeus, R.C.; Marquetant, R.; Strasser, R.H. Trans regulation of the $\alpha 2$-adrenergic signal transduction pathway by chroni-blockade. J. Cardiovasc. Pharm. 2005, 45, 253-259. [CrossRef]

45. Li, R.J. The role of histidine in metabolism. Prog. Physiol. Sci. 1985, 2, 80-82.

46. Duan, J.; Liang, Z.; Yang, C.; Zhang, J.; Zhang, L.; Zhang, W.; Zhang, Y. Rapid protein identification using monolithic enzymatic microreactor and LC-ESI-MS/MS. Proteomics 2006, 6, 412-419. [CrossRef] [PubMed]

47. Wang, Y.; Hao, J.; Gao, W.; Liu, Z.; Wu, S.; Jing, S. Study on hemostatic activities of the rhizome of Paris bashanensis. Pharm. Biol. 2013, 51, 1321-1325.

48. Lu, W.J.; Lee, J.J.; Chou, D.S.; Chou, D.S.; Jayakumar, T.; Fong, T.H.; Hsiao, G.; Sheu, J.R. A novel role of andrographolide, an NF-kappa B inhibitor on inhibition of platelet activation: The pivotal mechanisms of endothelial nitric oxide synthase/cyclic GMP. J. Mol. Med. 2011, 89, 1261-1273. [CrossRef] [PubMed]

49. Lemini, C.; Jaimez, R.; Franco, Y. Gender and inter-species influence on coagulation tests of rats and mice. Thromb. Res. 2007, 120, 410-419. [CrossRef] [PubMed]

50. Fan, P.C.; Ma, H.P.; Hao, Y.; He, X.R.; Sun, A.J.; Jiang, W.; Li, M.X.; Jing, L.L.; He, L.; Ma, J.; et al. A new anti-fibrinolytic hemostatic compound 8-O-acetyl shanzhiside methylester extracted from Lamiophlomis rotata. J. Ethnopharmacol. 2016, 187, 232-238. [CrossRef] [PubMed]

51. Vesna, K.; Ivana, F.; Zorica, V. Effects of rutin and hesperidin and their Al (III) and Cu (II) complexes on in vitro plasma coagulation assays. Molecules 2011, 16, 1378-1388.

52. Sheu, J.R.; Hung, W.C.; Wu, C.H.; Lee, Y.M.; Yen, M.H. Antithrombotic effect of rutaecarpine, an alkaloid isolated from Evodia rutaecarpa on platelet plug formation in in vivo experiments. British J. Haematol. 2000, 110, 110-115. [CrossRef] [PubMed]

53. Simkhada, J.R.; Cho, S.S.; Mander, P.; Choi, Y.H.; Yoo, J.C. Purification, biochemical properties and antithrombotic effect of a novel Streptomyces enzyme on carrageenan-induced mice tail thrombosis model. J. Thromb. Res. 2012, 129, 170-182. [CrossRef]

54. Devaraja, S.; Girish, K.S.; Devaraj, V.R.; Kemparaju, K. Factor Xa-like and fibrin (ogen)olytic activities of a serine protease from Hippasa agelenoidesspider venom gland extract. J. Thromb. Thrombolys 2010, 29, 119-126. [CrossRef] [PubMed] 
55. Majumdar, S.; Dutta, S.; Das, T.; Chattopadhyay, P.; Mukherjee, A.K. Antiplatelet and antithrombotic activity of a fibrin (ogen)olytic protease from Bacillus cereus strain FF01. Int. J. Biol. Macromol. 2015, 79, 477-489. [CrossRef] [PubMed]

56. Mais, E.; Alolga, R.N.; Wang, S.L.; Linus, L.O.; Yin, X.; Qi, L.W. A comparative UPLC-Q/TOF-MS-based metabolomics approach for distinguishing Zingiber officinale Roscoe of two geographical origins. Food Chem. 2017, 240, 239-244. [CrossRef]

(C) 2019 by the authors. Licensee MDPI, Basel, Switzerland. This article is an open access article distributed under the terms and conditions of the Creative Commons Attribution (CC BY) license (http://creativecommons.org/licenses/by/4.0/). 